\title{
Factors that Optimize Engagement for Diverse Learners at Arts Performances for Young Audiences
}

Don Glass ${ }^{1}$

Annie K. Schulz Begle ${ }^{1}$

Jenelle M. Hallaert ${ }^{1}$

The John F. Kennedy Center for the Performing Arts

Abstract: Field trips to museums and performing arts centers are not a frequent activity for most students, so how do cultural organizations learn how to make the most of these limited but potentially valuable "gateway experiences" towards increased arts participation? This paper examines the development of a short engagement survey instrument that was administered during three seasons of performances across art forms, grade levels, and student populations. The findings feature three statistically significant factors that may optimize positive engagement in the arts experience for students: prior experience of performances, lessons in the art from, and preparation for the performance. However, when the data is disaggregated by students who attend Title I schools, English learners, and students with disabilities, not all the factors predict higher positive engagement. The factor that may work across all populations and exclusively for students with disabilities is preparation. Practical implications for audience recruitment, accessibility supports, and learning design for diverse learners are then discussed.

Keywords: Arts Education, Special Education, Arts Participation, Engagement, Performances for Young Audiences

\footnotetext{
${ }^{1}$ The John F. Kennedy Center for the Performing Arts. Correspondence concerning this article should be addressed to Don Glass, P.O. Box 101510. Arlington, VA 22210. Email: dglass@kennedy-center.org
} 
Factors That Optimize Engagement for Diverse Learners

\section{Introduction}

Gifts of the Muse (McCarthy, Ondaatje, Zakaras, \& Brooks, 2004) was a watershed publication about the development of arts participation that argued for the value of both the intrinsic and instrumental outcomes for the arts. We know from this report that many active adult arts participants are able to identify an arts "gateway experience" in younger life that was a powerful factor in later participation in art-making and performance/museum attendance. The report identifies theoretical contributing factors that are relevant to this paper, particularly early positive engagement with quality arts experiences.

"The key aspect of these initial experiences for future arts involvement is that the arts experience itself...engages the participant enough that he or she develops a positive attitude toward the arts and the possibility of future arts involvement. Whether this occurs may well depend on whether the initial experience is appropriate to the individual's age, interests, and life experience" (Ibid, pp. 55).

Because school field trips may not be frequent because of resource limitations and scheduling, community arts and cultural partners need to design to make the most out of these arts experiences. To inform this design, the research team developed and administered a survey instrument to measure student engagement after field trips to performances over three performance seasons. This paper examines student engagement in relation to prior experience in the art form, instruction in the art form, and preparation for the field trip. The findings are disaggregated by varied student populations so that we can predict what may work for whom under what conditions. The findings are being used to better understand what factors may optimize student engagement, and then to intentionally design for meaningful participation in learning across the whole experience for a diverse range of young people. Hopefully this datainformed investment may increase the likelihood of any of these high quality arts experiences to become a "gateway" to further arts participation.

\section{Literature}

Recent arts education research has explored the impact of field trips to cultural institutions on varied student outcomes. This study focused on what factors before the field trip may help to optimize that experience. We selected engagement as our key outcome to be a 
Factors That Optimize Engagement for Diverse Learners

consistent and reliable measure across a varied range of arts experiences, as well as because engagement plays a powerful role as an attentional gateway to further learning.

\section{Field Trips}

A field trip is an excursion to a location outside of the classroom with educational intent, where students gain an experiential connection to ideas and subject matter (Tal \& Morag, 2009). Davidson, Passmore, and Anderson (2010) argue that field trips "promote tenets of constructivist and experiential learning theories: connecting to students' prior knowledge and experiences, tapping into students' interests, and motivating students to learn more about the topics introduced at the site" (p. 124). All of these aspects may contribute to student engagement. Furthermore, the complex nature of field trips encompass a broader scope of learning experiences that go beyond cognitive processing and tap in to affective and psychomotor domains. These stimulating environments can spark curiosity, develop appreciation, refine personal interests, and support identity development (Davidson et al., 2010).

Greene, Kisida, and Bowen (2014), argue that culturally enriching experiences for students living in poverty are important for their "critical thinking skills, historical empathy, tolerance, and becoming art consumers" (p. 85) compared to advantaged students. Cultural field trips may produce significant benefits for students. Researchers suspect that being in the presence of real-time performers immerses students into a larger world that broadens their curiosity, perception, and acceptance (Greene, Erickson, Watson, \& Beck, 2018; Greene, Kisida, \& Bowen, 2014). Even though field trips can be costly, time-sensitive, and challenging to coordinate, even a single visit to an art museum may help students ask complex questions about museum content, accept multiple interpretations of artwork, think critically about material properties, and recall emotional reactions (RK\&A Inc., 2018). School-based field trips tend to be the first encounter students have with museums and performances, and may become a gateway experience. These first encounters can be defining developmental moments that cultivate students' future arts participation (McCarthy \& Jinnett, 2001), particularly for students from disadvantaged backgrounds (high-poverty and rural areas).

There exist gaps in the literature on field trips which need to be addressed by researchers. Despite the promising field of researching informal learning experiences on students' trips to 
Factors That Optimize Engagement for Diverse Learners

different sites, studies done about school-organized trips to performing art centers are rare. The most studied sites for field trips include museums and galleries (e.g. Wolins et al., 1992; Griffin, 2004; Kisiel, 2006), zoos or wildland areas (e.g. Bixler et al., 1994, Davidson et al., 2010), and parks (e.g. Nielsen et al., 2009; Farmer et al. 2007). For student trips to performing art centers, research typically exists on the level of community extracurricular activities (e.g. Eccles \& Barber, 1999), rather than school-organized performances. In addition, there is not yet enough focus on studying field trip experiences of students who attend Title I schools, students with disabilities, or students who are English learners. The present study provides initial context for addressing these more complex questions in the future.

\section{Engagement}

Student engagement is predominantly conceptualized as a typology of behavioral, cognitive, and emotional/affective dimensions (Appleton et al., 2008; Fredericks et al., 2004). Behavioral engagement can be broadly defined as participation and refers to student involvement in academic, social or extracurricular activities. It also includes effort made to pay attention to a specific activity. (de Vreede, et al, 2019) Pendakur, Quaye, \& Harper, (2020), argue that engagement is not only behavioral participation, but also requires students to understand concepts and experience emotions. Cognitive engagement typically focuses on students' investments in the process of various academic tasks such as thinking, reasoning, and comprehension (Fredericks et al., 2004; Lawson \& Lawson, 2013). Cognitive engagement includes connecting prior knowledge to new knowledge. (Greene, 2015) It describes the ways in which students think deeply about ideas and concepts, how they make meaning of the material presented to them, and how they use self-regulating and metacognitive strategies to master academic content (Cleary \& Zimmerman, 2012; Lam, Wong, Yang, \& Liu, 2012). Emotional engagement focuses on students' range of attitudes or emotions in response to people, objects, and places. It includes students' levels of interest, enjoyment, happiness, boredom, and anxiety during academic activity (Appleton et al., 2008; de Vreede, et al, 2019; Pekrun \& LinnenbrikGarcia, 2012).

Contemporary research is highlighting the impact of emotions in student engagement by examining how different emotions shape engagement and the various ways students can manage their emotions to further their engagement (Pekrun \& Linnenbrink-Garcia, 2012). Similarly, 
engagement is related to the personal connections students make with the arts performance. Lamborn et al. (1992) argues activities that supply real-world connections to students have been identified as significant contributors to student engagement. In today's increasingly diverse society, students from different social and cultural backgrounds bring to school vastly different identities and perspectives, challenging their educators to find more effective ways to connect with their lives and personal experiences. Lawson \& Lawson (2013) emphasizes cultural relevance, which refers to students' emotional and cognitive reactions when an academic activity holds personal significance (Guthrie et al., 2012), as a significant cognitive and affective indicator of student engagement. Based on these insights from the literature, the degree of personal significance found within arts performances for students may impact their level of engagement and learning, as well as predict future arts participation. The present study draws on each of the types of student engagement.

\section{Factors of Student Engagement}

\section{Prior Knowledge and Experience}

Identifying and activating students' prior knowledge may foster engagement. Research in cognitive engagement and motivation suggests that students' conscious decisions about whether to engage in instructional content often depends on their sense of control and ability to do the work (Headden \& McKay, 2015). Characteristics of environments that create a balance between behavioral, cognitive, and affective engagement with regard to prior knowledge include students clearly identifying and activating their prior knowledge, as well as linking their prior knowledge to new learning (Almarode \& Miller, 2013). In this study, two of the variables measure prior experience and knowledge through items about lesson taking in the art form, and past experiences at similar performances.

\section{Preparation}

Brown and Ratzkin (2011) argue that pre-performance preparation plays an important role in contextualizing audiences to build up their anticipation, potentially increasing their engagement in the upcoming performance. Preparation materials that invite students to acquire prior knowledge about a particular arts performance before attending the show may optimize the experience, especially if the preparation materials are personally relevant to students. Preparation 
Factors That Optimize Engagement for Diverse Learners

is measured in this study by asking about whether discussions of the music, play, or dance occurred before the performance.

\section{Engagement Considerations for Priority Populations}

For students who are English learners, culturally relevant topics that are connected to their personal backgrounds, as well as culturally responsive teaching methods in class can significantly increase and transform their level of engagement (Feger, 2006; Gay, 2010). For students with disabilities, the literature provides a myriad of suggestions to motivate and engage students, including but not limited to, giving students choices, and providing activities that are relevant to students' life experiences and interests (Weiser, 2014). Finally, for students who live in poverty, the profound impact of repetitive stressors (e.g. violence, grief, loss, instability, and hardship) that manifest from living in poverty can significantly impact the way students learn. Despite these circumstances, children's brains are malleable and when they feel safe in a nurturing environment at school they tend to have better academic outcomes (Cantor, et al, 2019).

\section{Context}

Over the three year time-span of the study, the urban performing arts center served over 177,520 audience members with a range of day performances across multiple art forms offered to schools through the education division. The education division plays various roles in commissioning, scheduling, recruiting schools, and designing educational supports and activities for these performances for young people. The season is a series of performances designed for young audiences across the art forms of theater, music, and dance. Each performance has a suggested grade-level band for the developmental level of the student audience. Each production also has a different development process and set of educational activities depending on the art form and program. Each registered school is sent a packet of paper performance guides for teachers and students to prepare for the performance experience.

\section{Research Questions}

For this paper, we focused on the engagement scores across student populations, and then on what factors may account for some of the variance in those scores: 
Factors That Optimize Engagement for Diverse Learners

- How engaged were students in performances for young people by student populations?

- How does engagement vary by student population for the factors of lesson taking in an art form, having prior experience attending a performance, or preparation?

\section{Methods}

\section{Participants}

A population size was drawn from participation data from the 2015-2016 season. In 2016-2017, a student survey was administered to a probability sample of students to get a balanced sample across art forms (music, theater, and dance), and grade-bands (elementary, middle, and high). Depending on the mode of administration, many instances required additional convenience sampling based on a set of criteria applied to the school list for the targeted performance date (i.e., match of grade-band; public/public charter; locale; Title I status; manageable group size). When performances were cancelled or schools did not show up, performance dates were added to the sample until we approximated our targeted sample size. In 2017-2018 and 2018-2019, specific main offerings were selected in each art form and the same convenience sample strategy was applied.

Data was collected from 2,120 participants across three consecutive school years (20162017, 2017-2018, 2018-2019). Participants were students between third and twelfth grade in the grade bands of elementary school $(n=892,43.640 \%)$, middle school $(n=736,36.008 \%)$, and high school $(n=416,20.352 \%)$. Students were recruited from public schools within the districts within a school day round trip driving distance of the performing arts center. IntegReview of Austin, TX, an Independent Review Board, approved the study [2016-3.2]. Informed consent was waived except for identified students with disabilities who required a written parental informed consent and a written student assent prior to the survey administration.

Three priority populations of students were disaggregated to examine differences, students who attended a Title I school ( $\mathrm{n}=1030,50.219 \%)$ (NCES School Title I Eligibility). English learners (EL) (n=319, 15.637\%) (self-identified), and students with disabilities (SWD) $(\mathrm{n}=112,5.782 \%)$ (recruited). (See Table 1.) There were also cases of co-occurrence of priority populations: 215 (10.897\%) of a total of 1973 participants were both from Title I schools and English learners; 22 (1.147\%) out of 1918 participants were English learners with a disability; 14 
Factors That Optimize Engagement for Diverse Learners

$(0.745 \%)$ of 1879 participants who were from Title I schools and had a disability; and 1 $(0.047 \%)$ of 2120 participant was from a Title I school and was an English learners with a disability. Data missingness was below $4 \%$ for all main variables except for the identification of students with disabilities variable, which was $8.6 \%$.

Table 1

Demographics of Participants per Populations

\begin{tabular}{|c|c|c|c|c|c|c|c|c|}
\hline \multirow[t]{2}{*}{ Population Groups } & \multicolumn{2}{|l|}{ Total } & \multicolumn{2}{|c|}{ Elementary school } & \multicolumn{2}{|c|}{ Middle school } & \multicolumn{2}{|c|}{ High school } \\
\hline & $n$ & $\%$ & $n$ & $\%$ & $n$ & $\%$ & $n$ & $\%$ \\
\hline Overall $^{\mathrm{a}}$ & 2120 & $\begin{array}{c}100.00 \\
0\end{array}$ & 892 & 43.640 & 736 & 36.008 & 416 & 20.352 \\
\hline $\begin{array}{l}\text { Students from Title I } \\
\text { Schools }^{\mathrm{b}}\end{array}$ & 1030 & 50.219 & 641 & 62.598 & 156 & 15.234 & 227 & 22.168 \\
\hline English Learners (EL) & 319 & 15.637 & 174 & 55.591 & 94 & 30.032 & 45 & 14.377 \\
\hline $\begin{array}{l}\text { Students with Disabilities } \\
\text { (SWD) }\end{array}$ & 112 & 5.782 & 13 & 11.818 & 75 & 68.182 & 22 & 20.000 \\
\hline
\end{tabular}

Note. $N=2120$. Co-occurrence of populations (EL*Title I, $\mathrm{n}=215(10.9 \%)$; EL*SWD, $\mathrm{n}=22(1.1 \%)$; SWD*Title I, $\mathrm{n}=14(0.7 \%))$. a. Missing data $(\mathrm{n}=66)$; b. Data gathered from https://nces.ed.gov/ccd/schoolsearch/

To include these populations, several strategies were employed. Students with disabilities were intentionally recruited from designated public and private schools that serve special populations. On a few occasions, pre-registered classes were identified as coming from these schools and coded in the data-set. English learners were identified through self-report on the survey asking them if they were learning English as an additional language. Students who may be living in poverty were coded using the Title I status of the school that they attended because we did not have student level data like FARM. School participation data was collected from school registration forms. 
Factors That Optimize Engagement for Diverse Learners

The study was designed to disaggregate data for these priority populations. These student groups were designated as students who are living in poverty and are served by schools with high concentrations of students living in poverty, English learners, and students with disabilities. In addition to being influenced by the data collection efforts of the United States Department of Education, Office of Civil Rights, the study design followed recommendations in the Universal Design for Evaluation Checklist (Sullivan Sulewski \& Gothberg, 2013), and the Arts and Special Education Research Map (Kennedy Center, 2018) for including diverse respondents.

All of the data was gathered into an omnibus dataset, checking to make sure that there were no statistically significant differences across the three years in terms of sampling and administration. The large and varied population across the different program art forms, types, and educational activities, makes for a large sample size with a lot of variance to explore. And by design, we also disaggregated multiple priority population groups to understand what factors may work better for whom.

\section{Measurement}

\section{Engagement Survey}

The student survey consisted of eleven items with a six item engagement subscale designed by the research team. The engagement scale was conceptually based on constructs of emotional (After seeing the music performance or rehearsal today, how much did you like it?; Would you tell a friend to come to this music performance?), cognitive (Did any piece of music you heard remind you of music you have heard before?; Do you listen to music like this?), and behavioral (How much were you paying attention to the music performance or rehearsal while it was happening?) The other items in the student survey measured students' prior experience attending a live performance (Have you ever been to a show in a theater/concert hall?), students' preparation in their classrooms before attending the show (Did you and your class talk about the show before coming to the performing arts center today?), and if students had taken lessons in acting, music, or dance (Have you ever taken acting/music/dance lessons?) The engagement scale examined students' engagement in relation to their present-moment experience viewing of a live performance. 
Factors That Optimize Engagement for Diverse Learners

\section{Survey Administration}

Survey data was gathered using a range of procedures across the three years including digital tablets in theater, paper surveys in school, paper surveys in theater, and on-your-owndevice using a QR code/URL. Students had the choice of responding to the survey items in English or Spanish. Secondary data was collected from the performing arts center's school performance brochure, registration data, and the National Center for Education Statistics (NCES) at the school-level.

To support all learners in responding accurately to the survey, efforts were made to make the administration flexible, and the content understandable to a range of students. The survey questions were assessed at a readability level for grade 4 (Flesch-Kincaid Grade Level 4.0) with English learners in mind (IELTS Level 4-5). Students were given the option to respond to the survey in English or Spanish. For students with disabilities, the performing arts center's accessibility office liaised with the accompanying teachers to remove any physical or mobility barriers, and the Research and Evaluation team provided extra time, multiple options, and supports to respond to the survey including: paper or digital surveys using tablet computers; braille, text to speech software with headsets; and proctored administration with a data collector. One group opted to respond digitally to the survey back at the school site where the assistive technology was familiar to the students. These flexible options and supports for administration did not show any statistically significant differences to the standard administration procedures.

\section{Factor Analysis}

To validate the engagement scale psychometrically, factor analysis was performed with the original six questions and the properties of reliability were examined. Before conducting a factor analysis, data was screened for missingness. Sixty five cases out of 2120 participants were found to be missing audience engagement data, which represented approximately $3 \%$ of all participants and was within an acceptable range. A final sample size of 2055 participants was used for factor analysis, with a ratio of 342 cases per variable.

As a first approach, the research analyst conducted an exploratory factor analysis. Although the small number of items were conceptually related to three types of engagement (emotional, cognitive, and behavioral) the factor analysis indicated one factor for the engagement scale. The 
factorability of the six engagement items was examined through the criteria of Kaiser-Meier-Olkin test of sampling adequacy, which yielded a value of .781, well above the generally used threshold of .600 , and close to the recommended value of .800 . Bartlett's test of sphericity was also used, and was significant $\left(\chi_{2}(15)=2290.903, p<.001\right)$. The diagonal values of the anti-image correlation matrix were all between .734 and .855 . Given all of these criteria, factor analysis was considered to be suitable with the six items, for which both scree plot and eigen values criteria indicated that the scale had a single factor. This factor alone explained $42 \%$ of the variance in audience engagement.

After this initial analysis, one item ("Was the trip to the performing arts center what you expected?") was eliminated because of doubts about its validity (the item seemed to be measuring something different than engagement), which was also reflected in the factor loading, substantially lower than the rest. In addition, this item had a positive skew effect, with $74 \%$ of participants reporting the trip to have been what they expected.

For the final stage, a confirmatory factor analysis of the remaining five items was conducted, with the model postulated a priori being that of a single factor of audience engagement. The goodness-of-fit criteria used in this case were Chi-square divided by the degrees of freedom (CMIN/DF; < 2 or 3) root mean square error of approximation (RMSEA; <.06 to .08), comparative fit index (CFI; >.95), standardized root mean square error residual (SRMR; <.08), and Tucker-Lewis Index (TLI; >.95) with cut-off indices recommended by Schreiber, Stage, King, Nora, and Barlow (2006). The resulting values were $\mathrm{CMIN} / \mathrm{DF}=11.239 ; \mathrm{RMSEA}=.072 ; \mathrm{CFI}=.974 ; \mathrm{SRMR}=.035$, and TLI $=.947$. Except for the proportion of Chi-square value and degrees of freedom, all the indices fit adequately, indicating that the hypothesized single factor model represented the best fit to the data. Factor loadings ranged from .389 to .618 .

Internal consistency of the scale was examined using Cronbach's alpha, which was acceptable: .703. A global score of engagement was created based on the mean of the items of this scale. Higher scores indicated greater audience engagement with the performance. Descriptive analyses of this global score indicated the average was 2.997 in a scale that ranged from 1 to 4 , with a standard deviation of .602 The skewness (-.653) and kurtosis (.294) were well within an acceptable range for the assumption of a normal distribution, and the examination of the histogram suggested that the distribution appeared normal.

Overall, these analyses indicated the unidimensionality of this audience engagement scale, which has shown moderate internal consistency. One of the six items was eliminated, however the 
Factors That Optimize Engagement for Diverse Learners

original factor structure of a single factor was maintained. A normal distribution was observed for the global score data, thus the data were well suited for further parametric statistical analyses.

\section{Results}

The first research question asks how engagement varied by student populations. In regards to the three priority populations, there were no significant effects of Title I status or being an English Language Learner on engagement. There was a significant difference in engagement depending on whether the student had a disability or not $(\mathrm{F}(1,1929)=13.407 ; p=$ $.000)$. Students with a disability appeared to be less engaged $(\mathrm{M}=2.805, \mathrm{SD}=.548, \mathrm{n}=109)$ than participants with no disability $(\mathrm{M}=3.019, \mathrm{SD}=.596, \mathrm{n}=1822)$.

Table 2

Descriptive Statistics for Population Groups

\begin{tabular}{|c|c|c|c|c|c|c|c|c|}
\hline \multirow[t]{2}{*}{ Measure } & \multicolumn{2}{|c|}{ Overall $^{\mathrm{a}}$} & \multicolumn{2}{|c|}{$\begin{array}{c}\text { Students from Title I } \\
\text { Schools }\end{array}$} & \multicolumn{2}{|c|}{ English Learners (EL) } & \multicolumn{2}{|c|}{$\begin{array}{c}\text { Students with Disabilities } \\
\text { (SWD) }\end{array}$} \\
\hline & $M$ & $S D$ & $M$ & $S D$ & $M$ & $S D$ & $M$ & $S D$ \\
\hline Engagement & 2.997 & .602 & 3.038 & .570 & 3.029 & .585 & 2.805 & .548 \\
\hline $\begin{array}{l}\text { Prior } \\
\text { Experience }\end{array}$ & .802 & .398 & .775 & .418 & .740 & .440 & .809 & .395 \\
\hline Lessons & 1.936 & .834 & 1.990 & .845 & 1.889 & .815 & 1.537 & .716 \\
\hline
\end{tabular}

Note. $N=2120$. a $n=2055$

The second research question asks how three factors may explain some of the variance in engagement scores. In Table 2, for the overall population there was a significant and positive prediction of engagement from preparation $\left(\mathrm{F}(1,2033)=91.942, p=.000 ; \mathrm{R}^{2}=.043\right)$, although explaining only a small proportion (4\%) of variance in engagement (See Table 3). Similarly, a $6 \%$ of the variance in student engagement $\left(\mathrm{F}(1,2035)=130.084, p=.000 ; \mathrm{R}^{2}=.060\right)$ was positively and significantly predicted by having taken prior lessons. Finally, there was a significant difference between those who had attended a prior show and those who had not (F (1, 
Factors That Optimize Engagement for Diverse Learners

2039) $=9.749 ; p=.002$ ). Those who had been to a show had a higher score on the engagement measure.

Table 3

Analysis of Variance (ANOVA) and Regression of Study Variables on Engagement

\begin{tabular}{|c|c|c|c|c|c|c|c|c|c|c|c|c|}
\hline \multirow[t]{2}{*}{ Variable } & \multicolumn{3}{|c|}{ Overall } & \multicolumn{3}{|c|}{ Title I } & \multicolumn{3}{|c|}{ English Learners (EL) } & \multicolumn{3}{|c|}{$\begin{array}{c}\text { Students with } \\
\text { Disabilities (SWD) }\end{array}$} \\
\hline & $B$ & $R^{2}$ & $p$ & $B$ & $R^{2}$ & $p$ & $B$ & $R^{2}$ & $p$ & $B$ & $R^{2}$ & $p$ \\
\hline $\begin{array}{l}\text { Prior } \\
\text { Experience } \\
\text { (ANOVA) }\end{array}$ & -- & -- & $.002 *$ & -- & -- & $.019 *$ & -- & -- & .837 & -- & -- & .568 \\
\hline $\begin{array}{l}\text { Lessons } \\
\text { (Regression) }\end{array}$ & .177 & .060 & $.000 *$ & .154 & .052 & $.000 *$ & .174 & .059 & $.000 *$ & .001 & .000 & .990 \\
\hline $\begin{array}{l}\text { Preparation } \\
\text { (Regression) }\end{array}$ & .135 & .043 & $.000 *$ & .121 & .042 & $.000 *$ & .176 & .078 & $.000 *$ & .246 & .179 & $.000 *$ \\
\hline
\end{tabular}

Note. $* p<.05$.

Although statistically significant results were found for all three factors, we wanted to see how these might hold or vary across our three priority population groups. For students attending a Title I school there was a significant and positive prediction of having prepared for the performance on engagement $\left(\mathrm{F}(1,1016)=44.643, p=.000 ; \mathrm{R}^{2}=.042\right)$ (Table 3$)$, with those who prepared before the performance scoring higher in engagement and accounting for a $4 \%$ of variance in engagement. The prediction of having taken lessons over engagement was also significant for this population $\left(\mathrm{F}(1,1016)=55.668, p=.000 ; \mathrm{R}^{2}=.052\right)$, accounting for a variance of $5 \%$, and in the same direction as the other populations. The engagement difference between prior attendance or not was significant for students from Title I schools $(\mathrm{F}(1,1017)=$ $5.501 ; p=.019)$. Having previously attended a show or performance was associated with greater engagement.

For the English learner (EL) population there was a significant and positive prediction of engagement $\left(\mathrm{F}(1,313)=26.375, p=.000 ; \mathrm{R}^{2}=.078\right)$ for those who prepared before seeing a 
performance compared to those EL students who did not, accounting for close to $8 \%$ of variance. Having taken previous lessons significantly predicted engagement for $\operatorname{EL}(\mathrm{F}(1,313)=19.564, p$ $\left.=.000 ; \mathrm{R}^{2}=.059\right)$, and explained $6 \%$ of variance. Having previously attended a performance did not seem to matter.

Students with disabilities demonstrated a positive and statistically significant $(\mathrm{F}(1,106)$ $\left.=23.189 ; p=.000 ; \mathrm{R}^{2}=.179\right)$ prediction of engagement utilizing preparation. Prior discussion accounted for $18 \%$ of variance in Engagement scores. For students with disabilities, it appears that the engagement in the performance comes almost entirely from preparing prior to the performance. The effect of prior experience or lessons was not significant.

\section{Discussion}

\section{Implications, Limitations, and Further Research}

This study used student engagement as a consistent measure across a range of art forms, productions and performances, as well as a range of student grade-levels and populations. Beyond the high quality performance, we were looking for factors that had a statistically significant effect on emotional engagement for young audiences. In this discussion we look into these aspects that explain some of the variance in engagement and disaggregate the findings by population groups to get insights into what may work better for whom. We discuss implications and limitations of the findings, and suggest further research pathways.

As predicted, we saw that the factors of having prior experience at a performance, lesson taking in the art form, and preparation each contributed to higher affective engagement for the overall sample population. In other words, the more interaction students experienced with the art form prior to attending the performance, the higher their engagement level.

The unique contribution of this study is to show which factors may work differently for which student population when the data is disaggregated. Another way to look at this is the following "what works for whom" summary:

- Overall: It seems all three aspects of prior interaction with the art form played a significant role in the level of engagement of students. Higher student engagement was found for students who have had prior experience attending performances, previously taken lessons in a relevant art form, and received preparation prior to attending the Glass, Schultz Begle, and Hallaert. (2020). Pre-print DOI 10.31219/osf.io/2rcwq 
Factors That Optimize Engagement for Diverse Learners

performance, with each separately contributing to higher engagement at the time of the performance in the performing arts center.

- Students from a Title I School: Consistent with the overall finding, all three factors supported greater engagement for students attending Title I schools. These factors, again, are to have experience attending performances, to have previously taken lessons in a relevant art form, and to have prepared prior to the performance.

- English learners: For students who are English learners the factors of having previously taken lessons in a relevant art form, and having prepared prior to the performance supported greater engagement.

- Students with disabilities: For students with disabilities, the only factor that supported greater engagement came entirely from preparing prior to the performance.

Although the overall findings include prior experience of attending performances, this seems to matter less for two of the priority populations. Taking lessons in the relevant art form seems to make a difference for English learners and for students from Title I schools. Although the provision of arts lessons and the planning of out of school field trips are not the responsibility of cultural organizations, an implication for these findings could be to build relationships and strategically recruit schools. Further research is required to examine the importance of collaboration with schools in terms of recruitment of populations/grade-levels at strategic timepoints (e.g., inviting fourth graders to an educational orchestral concert during the year that they choose to begin instrumental music lessons), and an alignment of in-school and out-of-school instructional goals, activities, and materials (e.g., reading and analyzing a text in school that has been turned into a theatrical play.) This study did not collect in-school preparation data that could be accurately aligned with the student level data. A future study could be designed to match student level demographic and response data (i.e., emotional, cognitive, and behavioral engagement; learning assessments) to lesson taking and preparation activity types in and out of schools.

We do not know from the study data whether students with disabilities attend out of school performances more or less often than other students. We also do not know from the study data whether arts lessons are available to students with disabilities to the same degree as other 
students. Regardless of the availability of the arts lessons, we know from the study findings that preparation is an important factor for students with disabilities. In addition, preparation is also a factor that contributes to the engagement of all the other populations. We also know that students with disabilities are less positively engaged than their counterparts, suggesting that preparation strategies to increase engagement are critical to develop further. Designing and testing preparation materials for supporting students with disabilities would be a smart investment and also may be helpful to other population groups. Enhanced performance guides based on good learning design may be a productive strategy here (e.g., clear learning goals, connections to background knowledge, culturally relevant examples, vocabulary/language supports, multimodal representations of content, information chunking, alternative text, text-to-speech, captioning, and audio description). (Glass et al, 2013; Meyer, et al, 2014) There also may be other more robust strategies for preparing young people for a performance and the field trip experience (e.g., classroom pre-visits, videos with artists, social stories, and other emotional selfregulation strategies to manage anxiety, and provide expectations for a safe, non-distracting environment, etc.) (Kennedy Center, 2015).

There are a few study limitations that should be considered when interpreting the data and findings. The sample was not randomized, and student groups were selected at the school level using a set of criteria and by convenience. Because we did not have access to student level demographic data, we relied on the Title I designation of the school as a proxy to identify students living in poverty, a self-report question to identify possible English learners, as well as used a direct recruitment strategy to include students with disabilities which unfortunately gave us a smaller sample size for this population.

Specifically regarding the lack of individual student data, we could not further categorize students with disabilities as having mobility or sensory disabilities that may require a 504 plan, nor do we know how many of the students have an intellectual or learning disability that would require an IEP. Students may also have a 504 plan and an IEP. Each of these sub-groups may vary in engagement and the possible supports for improving that engagement. In addition, there may be students with disabilities represented in the overall sample that were not identified in the data-set. The national percentage of enrolled public school students who receive services under IDEA is $14 \%$ (NCES, 2019), but we do not know how likely it is for students with disabilities to 
Factors That Optimize Engagement for Diverse Learners

participate in field trips compared to the overall student population. A future research study should consider randomization and negotiating access with the district central office for student level data, and more intensive recruitment of schools that specialize in serving students with disabilities. An even larger sample size would allow for deeper analysis of co-occurrence and intersectionality across population groups.

\section{Conclusion}

This is a correlational study that has examined the association of several factors to the engagement of students for out of school arts performances. The findings can be used to look at what factors may predict the likelihood of a young person being more positively engaged on average by high quality arts performances regardless of the art form. To get to more nuanced predictions, we also disaggregated the data by the priority populations of students who may be living in poverty, English learners, and students with disabilities. By doing so, we were able to identify the critical and only factor that seems to matter for students with disabilitiespreparation, which also matters for the other populations.

The study contributes a short manageable survey instrument in English and Spanish that has good readability statistics for diverse learners, confirmed validity for measuring engagement, and an acceptable level of reliability for consistent data collection. This paper also provides some justification and strategies for including priority populations in the design of instruments, survey administration, and data analysis. Considering that preparation is the only positive engagement strategy for students with disabilities, and that this population is currently positively engaged less than the other population groups, it indicates a growth area for expanding pre-visit resources and activities, as well as considering differentiation strategies and accessibility supports to address variation in diverse learners. A solid investment in these resources that may be required for students with disabilities, and may also be useful for all audiences to optimize potential "gateway experiences" to future arts participation. Or as universal design advocates say, if supports and options are, "essential for some, and useful for all," then why not design for this variability? 
Factors That Optimize Engagement for Diverse Learners

Acknowledgments: John F. Kennedy Center for the Performing Arts Research and Evaluation with contributions from Bina Ali, Gail Burnaford, Stephanie McKeel, Charles Beekman, Sarah K, Jessica Swanson, Sarah Schoenfelder, and Jenna Gabriel..

\section{Author Notes:}

The author(s) disclosed receipt of the following financial support for the research, authorship, and/or publication of this article: This work was supported by the U.S. Department of Education under the Arts in Education National Program grant number: U351F150001.

The content of this paper does not necessarily represent the policy of the U.S. Department of Education. You should not assume endorsement by the federal government.

We have no conflicts of interest to disclose.

IRB Protocol Number and Name of Research Study: Student Engagement in Kennedy Center Performances, Events and Tours. IntegReview IRB, Austin, TX [2016-3.2] 
Factors That Optimize Engagement for Diverse Learners

\section{References}

Almarode, J. \& Miller A.M. (2013). Captivate, activitate, and invigorate the student brain in science and math. Corwin.

Appleton, J. J., Christenson, S. L., \& Furlong, M. J. (2008). Student engagement with school: Critical conceptual and methodological issues of the construct. Psychology in the Schools, 45(5), 369-386. https://doi.org/10.1002/pits.20303

Bixler, R. D., Carlisle, C. L., Hammltt, W. E., \& Floyd, M. F. (1994). Observed fears and discomforts among urban students on field trips to wildland areas. The Journal of Environmental Education, 26(1), 24-33. https://doi.org/10.1080/00958964.1994.9941430

Brown, A.S. \& Ratzkin, R. (2011). Making sense of audience engagement: A critical assessment of the efforts by non-profit arts organizations to engage audiences and visitors in deeper and more impactful arts experiences. The San Francisco Foundation.

Cantor, P., Osher, D., Berg, J., Steyer, L., \& Rose, T. (2019). Malleability, plasticity, and individuality: How children learn and develop in context. Applied Developmental Science, 23(4), 307-337. https://doi.org/10.1080/10888691.2017.1398649

Cleary, T.J., \& Zimmermann, B.J. (2012). A cyclical self-regulatory account of student engagement: Theoretical foundations and applications. In S.L. Christenson, A.L. Reschly, \& C. Wylie (Eds.), Handbook of research on student engagement (pp. 237-257). Springer. https://doi.org/10.1007/978-1-4614-2018-7_11

Davidson, S. K., Passmore, C., \& Anderson, D. (2010). Learning on zoo field trips: The interaction of the agendas and practices of students, teachers, and zoo educators. Science Education, 94(1), 122-141. https://doi.org/10.1002/sce.20356

Eccles, J. S., \& Barber, B. L. (1999). Student Council, Volunteering, Basketball, or Marching Band: What Kind of Extracurricular Involvement Matters? Journal of Adolescent Research, 14(1), 10-43. https://doi.org/10.1177/0743558499141003 
Factors That Optimize Engagement for Diverse Learners

Farmer, J., Knapp, D., \& Benton, G. M. (2007). An elementary school environmental education field trip: Long-term effects on ecological and environmental knowledge and attitude development. The journal of environmental education, 38(3), 33-42.

https://doi.org/10.3200/JOEE.38.3.33-42

Feger, M.V.. (2006). "I Want To Read": How Culturally Relevant Texts Increase Student Engagement in Reading. Multicultural Education, 13(3), 18-19.

https://doi.org/10.1080/10573569.2012.651078

Fredricks, J. A., Blumenfeld, P. C., \& Paris, A. H. (2004). School engagement: Potential of the concept, state of the evidence. Review of Educational Research, 74(1), 59-109. https://doi.org/10.3102\%2F00346543074001059

Gay, G. (2010). Culturally responsive teaching: Theory, research, and practice, 2nd edition. Teachers College Press.

Glass, D., Meyer, A. \& Rose, D. (2013). Universal Design and the Arts. Harvard Educational Review, 83 (1), 98-119.

Greene, J. P., Erickson, H. H., Watson, A. R., \& Beck, M. I. (2018). The play's the thing: Experimentally examining the social and cognitive effects of school field trips to live theater performances. Educational Researcher, 47(4), 246-254.

https://doi.org/10.3102\%2F0013189X18761034

Greene, J. P., Kisida, B., \& Bowen, D. H. (2014). The educational value of field trips: Taking students to an art museum improves critical thinking skills, and more. Education Next, 14(1), 78-87. https://www.educationnext.org/the-educational-value-of-field-trips/

Griffin, J. (2004). Research on students and museums: Looking more closely at the students in school groups. Science Education, 88(S1), S59-S70.

https://doi.org/10.1002/sce.20018

Guthrie J.T., Wigfield A., You W. (2012) Instructional contexts for engagement and achievement in reading. In: Christenson S., Reschly A., Wylie C. (eds) Handbook of Research on Student Engagement. Springer. https://doi.org/10.1007/978-1-4614-2018-7_29 
Factors That Optimize Engagement for Diverse Learners

Headden, S. \& McKay, S. (2015). Motivation matters: How new research can boost student engagement. Carnegie Foundation for the Advancement of Teaching. https://www.carnegiefoundation.org/wpcontent/uploads/2015/07/Motivation_Matters_July_2015.pdf

Kisiel, J. (2006). An examination of field trip strategies and their implementation within a natural history museum. Science Education, 90(3), 434-452. https://doi.org/10.1002/sce.20117

Lam, S., Wong, B.P.H., Yang, H., \& Liu, Y. (2012). Understanding student engagement with a contextual model. In S.L. Christenson, A.L. Reschly and C. Wylie (Eds.), Handbook of research on student engagement (pp. 403 - 419). Springer. https://doi.org/10.1007/978-1-46142018-7_19

Lamborn, S. D., Brown, B. B., Mounts, N. S., \& Steinberg, L. (1992). Putting school in perspective: The influence of family, peers, extracurricular participation, and part-time work on academic engagement. In F. M. Newmann (Ed.), Student engagement and achievement in American secondary schools (pp. 153 -181). Teachers College Press.

Lawson, M. A., \& Lawson, H. A. (2013). New conceptual frameworks for student engagement research, policy, and practice. Review of Educational Research, 83(3), 432-479. https://doi.org/10.3102\%2F0034654313480891

McCarthy, K. F., \& Jinnett, K. J. (2001). A new framework for building participation in the arts. RAND Corporation. https://www.rand.org/pubs/monograph_reports/MR1323.html

McCarthy, K.F., Ondaatje, E.H., Zakaras, L. \& Brooks, A. (2004). Gifts of the muse: Reframing the debate about the benefits of the arts. RAND Corporation. https://www.rand.org/pubs/monographs/MG218.html

Meyer, A., Rose, D.H., \& Gordon, D. (2014). Universal Design for Learning: Theory and practice. CAST Publishing. http://udltheorypractice.cast.org/

Nielsen, W. S., Nashon, S., \& Anderson, D. (2009). Metacognitive engagement during field-trip experiences: A case study of students in an amusement park physics program. Journal of Research in Science Teaching, 46(3), pp. 265-288. https://doi.org/10.1002/tea.20266 
Factors That Optimize Engagement for Diverse Learners

Pekrun, R., \& Linnenbrink-Garcia, L. (2012). Academic emotions and student engagement. In S.L. Christenson, A.L. Reschly and C. Wylie (Eds.), Handbook of research on student engagement (pp. 259-282). Springer. https://doi.org/978-1-4614-2018-7_12

Pendakur, S. L., Quaye, S. J., \& Harper, S. R. (2020). The heart of our work: Equitable engagement for students in US higher education. In S.J. Quaye, S.R. Harper, \& S.L. Pendakur (Eds.), Student engagement in higher education: Theoretical perspectives and practical approaches for diverse populations (3rd ed., pp. 1-16). Routledge.

Randi Korn \& Associates, Inc. (2018). Impact study: The effects of facilitated single-visit art museum programs on students grades 4-6: Summary Report and Discussion. https://www.arteducators.org/research/articles/377-naea-aamd-research-study-impact-of-artmuseum-programs-on-k-12-students

Schreiber, J. B., Stage, F. K., King, J. Nora, A., \& Barlow, E. A. (2006). Reporting structural equation modeling and confirmatory factor analysis results: A review. The Journal of Educational Research, 99, 323-337. https://doi.org/10.3200/JOER.99.6.323-338

Sulewski, J. \& Gothberg, J. (2013). Universal Design for evaluation checklist (4th ed.) Self-Published. https://comm.eval.org/viewdocument/universal-design-for-1

Tal, T., \& Morag, O. (2009). Reflective practice as a means for preparing to teach outdoors in an ecological garden. Journal of Science Teacher Education, 20(3), 245-262. https://doi.org/10.1007/s10972-009-9131-1

U.S. Department of Education, National Center for Education Statistics. (2019). Table 204.30. Children 3 to 21 years old served under Individuals with Disabilities Education Act (IDEA), Part B, by type of disability: Selected years, 1976-77 through 2018-19. https://nces.ed.gov/programs/digest/d19/tables/dt19_204.30.asp

VSA. (2017). The arts and special education: A map for research, Eds. Gail Burnaford, Jenna Gabriel, and Don Glass. Washington, DC. John F. Kennedy Center for the Performing Arts Office of VSA and Accessibility. https://www.kennedycenter.org/globalassets/education/networks-conferences--research/research--resources/vsa- 
Factors That Optimize Engagement for Diverse Learners

resources/parents-and-educators/35237406_the_arts_and_special_educationa_map_for_research.pdf

Weiser, B. (2014). Academic diversity: Ways to motivate and engage students with learning disabilities. Council for Learning Disabilities. http://www.council-for-learningdisabilities.org/wp-content/uploads/2014/07/Weiser_Motivation.pdf

Wolins, I. S., Jensen, N., \& Ulzheimer, R. (1992). Children's memories of museum field trips: A qualitative study. Journal of Museum Education, 17(2), 17-27.

https://doi.org/10.1080/10598650.1992.11510204 